\title{
The association between migrant status and transition in an ultra-high risk for psychosis population
}

\author{
Brian O'Donoghue ${ }^{1,2}\left(\right.$ Hellen Geros $^{1,2} \cdot$ Holly Sizer $^{1,2} \cdot$ Jean Addington ${ }^{3} \cdot$ G. Paul Amminger ${ }^{1,2,4} \cdot$ Carrie E. Beaden $^{5}$. \\ Kristin S. Cadenhead ${ }^{6}$. Tyrone D. Cannon ${ }^{7}$. Barbara A. Cornblatt ${ }^{8}$. Gregor Emanuel Berger ${ }^{9}$. Eric Y. H. Chen ${ }^{10}$. \\ Lieuwe de Haan ${ }^{11}$. Jessica A. Hartmann ${ }^{1,2}$. Ian B. Hickie ${ }^{12}$. Helga K. Ising ${ }^{13}$. Suzie Lavoie ${ }^{1,2}$. Ashleigh Lin $^{14}$. \\ Connie Markulev ${ }^{1,2}$. Daniel H. Mathalon ${ }^{15,16}$. Thomas H. McGlashan ${ }^{17}$. Nathan G. Mifsud ${ }^{1,2}$. Nilufar Mossaheb ${ }^{4}$ \\ Dorien H. Nieman ${ }^{11}$ - Merete Nordentoft ${ }^{18}$. Diana O. Perkins ${ }^{19}$. Anita Riecher-Rössler ${ }^{20}$. Miriam R. Schäfer ${ }^{1,2}$. \\ Monika Schlögelhofer ${ }^{4} \cdot$ Larry J. Seidman $^{21,22} \cdot$ Stephan Smesny $^{23} \cdot$ Andrew Thompson $^{1,2} \cdot$ Ming T. Tsuang $^{6}$. \\ Mark van der Gaag ${ }^{13,24}$. Swapna Verma ${ }^{25}$. Elaine F. Walker ${ }^{26}$. Stephen J. Wood ${ }^{1,2}$. Scott W. Woods ${ }^{17}$. \\ Hok Pan Yuen ${ }^{1,2}$. Alison Ruth Yung ${ }^{1,2,27} \cdot$ Patrick D. McGorry ${ }^{1,2} \cdot$ Barnaby Nelson ${ }^{1,2}$
}

Received: 13 September 2019 / Accepted: 8 December 2020 / Published online: 5 January 2021

\begin{abstract}
Purpose Migrant status is one of the most replicated and robust risk factors for developing a psychotic disorder. This study aimed to determine whether migrant status in people identified as Ultra-High Risk for Psychosis (UHR) was associated with risk of transitioning to a full-threshold psychotic disorder.

Methods Hazard ratios for the risk of transition were calculated from five large UHR cohorts $(n=2166)$ and were used to conduct a meta-analysis using the generic inverse-variance method using a random-effects model.

Results 2166 UHR young people, with a mean age of 19.1 years (SD \pm 4.5$)$ were included, of whom 221 (10.7\%) were first-generation migrants. A total of 357 young people transitioned to psychosis over a median follow-up time of 417 days (I.Q.R.147-756 days), representing $17.0 \%$ of the cohort. The risk of transition to a full-threshold disorder was not increased for first-generation migrants, $(\mathrm{HR}=1.08,95 \% \mathrm{CI} 0.62-1.89)$; however, there was a high level of heterogeneity between studies The hazard ratio for second-generation migrants to transition to a full-threshold psychotic disorder compared to the remainder of the native-born population was 1.03 (95\% CI 0.70-1.51).

Conclusions This meta-analysis did not find a statistically significant association between migrant status and an increased risk for transition to a full-threshold psychotic disorder; however, several methodological issues could explain this finding. Further research should focus on examining the risk of specific migrant groups and also ensuring that migrant populations are adequately represented within UHR clinics.
\end{abstract}

Keywords Migrants · Psychotic disorders · Ultra-high risk for psychosis

\section{Introduction}

Migrant status is one of the most replicated and robust risk factors for developing a psychotic disorder, with first- and second-generation migrants having at least double the risk for developing schizophrenia [1, 2]. One of the earliest studies to demonstrate this was by Odegaard in the 1930s, which showed that migrants from Norway living in the United

Brian O'Donoghue

brian.odonoghue@orygen.org.au

Extended author information available on the last page of the article
States had a higher incidence of hospital admission for schizophrenia compared to those born in the United States [3]. Since then, it has been demonstrated that migrants to countries such as the Netherlands, Denmark, Canada, England and Australia have a greater risk of developing a psychotic disorder [4-8]. The risk of psychotic disorders also varies according to the country of birth, for example, in Australia, it has been found that migrants from specific African countries, namely Ethiopia, Kenya, Sudan and Somalia can have an increased risk of up to ten times that of the native-born population [8]. It is not yet fully understood why migrants have an increased risk for psychotic disorders; however, a 
number of theories have been proposed, with the strongest being the experience of social adversity prior to, during and following migration [9]. Interestingly, a younger age at the time of migration is also associated with a greater risk for developing a psychotic disorder [10].

To gain a better understanding of this increased risk, the trajectory and development of psychotic disorders in migrant populations needs to be understood. The onset of a full-threshold psychotic disorder is typically preceded by a prodrome that can be characterized by sub-threshold psychotic symptoms and a decline in functioning [11]. As the prodrome can only be identified retrospectively following the onset of a full-threshold psychotic disorder, criteria has been developed in order to facilitate the prospective identification of young people who are at increased risk of developing a psychotic disorder [12-14]. A meta-analysis identified that $36 \%$ of young people identified as being at ultra-high risk for psychosis (UHR) 'transitioned' to a full-threshold psychotic disorder within a three-year period [15]. A large body of research over the last two decades has identified factors that are associated with an increased risk of transitioning to a full-threshold psychotic disorder from the UHR stage, such as symptoms, functioning and cognition [16]. However, despite the abundance of research demonstrating that migrant have an increased risk for developing a psychotic disorder, there is a relative dearth of knowledge on their risk in the UHR stage.

Two separate studies from the same youth mental health service found that migrants who were identified as UHR were not at an increased risk for transitioning to a full-threshold psychotic disorder $[17,18]$. However, both studies were likely to be unpowered. In a typical UHR cohort, a proportion of the total cohort will be migrants and approximately one third of the total cohort will transition if the cohort is followed up for a sufficient time. Therefore, a large cohort would be required to determine whether UHR migrants are at an increased risk for transitioning to a psychotic disorder. Therefore, this study aimed to pool the data from five large international studies and determine whether there is an association between migrant status and risk of transitioning to a full-threshold psychotic disorder from UHR stage.

\section{Methodology}

\section{Setting and sample}

This study consisted of five separate cohorts including individuals identified at being ultra-high risk for psychosis. The Dutch Early Detection Intervention Evaluation (EDIE-NL) study was a randomized controlled trial of cognitive behavioral therapy involving 196 UHR individuals aged 14-35 in six sites in the Netherlands [19]. The North American
Prodrome Longitudinal Study (NAPLS) was a longitudinal cohort study from eight programs in North America and it included 764 UHR individuals aged $12-35$ years [20]. The NEURAPRO study consisted of 304 UHR individuals aged 13-40 who participated in a randomized controlled trial on the effect of omega- 3 polyunsaturated fatty acids in ten sites across Australia, Asia and Europe [21]. The PACE400 cohort consisted of 416 UHR individuals aged 13-40 who participated in seven different research studies at the Personalized Assessment and Clinical Evaluation (PACE) clinic between 1993 and 2006 [22]. The PACE2012-2016 cohort consisted of 481 UHR individuals aged 15-24 who received care at the PACE clinic between 2012 and 2016 [17]. Altogether, participants came from ten countries. A summary of the individual studies is presented in Table 1 .

\section{Identification of eligible datasets}

Datasets of UHR/ CHR cohorts were identified as part of a related systematic review and the investigators of cohorts that included these UHR participants were contacted.

\section{Terminology and definitions}

The prodrome of a psychotic disorder can only be determined retrospectively and a number of different terms have been used to describe the putative prodromal state that has been used to prospectively identify individuals at greater risk for developing a psychotic disorder. The terms used include: Ultra-high risk for psychosis (UHR); the At-Risk Mental State (ARMS); Clinical High Risk for Psychosis (CHR) and the putative prodrome. For consistency and ease of reading, the term 'Ultra-High risk for psychosis' (UHR) will be used throughout this manuscript regardless of the term used in the original study.

Individuals were classified as first-generation migrants if they were born in another country to that in which the study was set. Second-generation migrants were defined as those who were born in the country in which the study was set but had at least one parent who was born in another country.

\section{Criteria for determining UHR status and transition}

In the EDIE-NL, NEURAPRO, PACE400 and PACE2012-2016 studies, the Comprehensive Assessment of the At-Risk Mental State (CAARMS) was used to determine UHR status and also transition [23]. In the PACE400 study, if the CAARMS data were not available for participants at follow-up, then the state public mental health records were used to determine whether transition occurred. In the NAPLS cohort, the Criteria of Prodromal Syndromes (COPS) and the Structured Interview for Prodromal Syndromes (SIPS) were used to determine the presence of the 


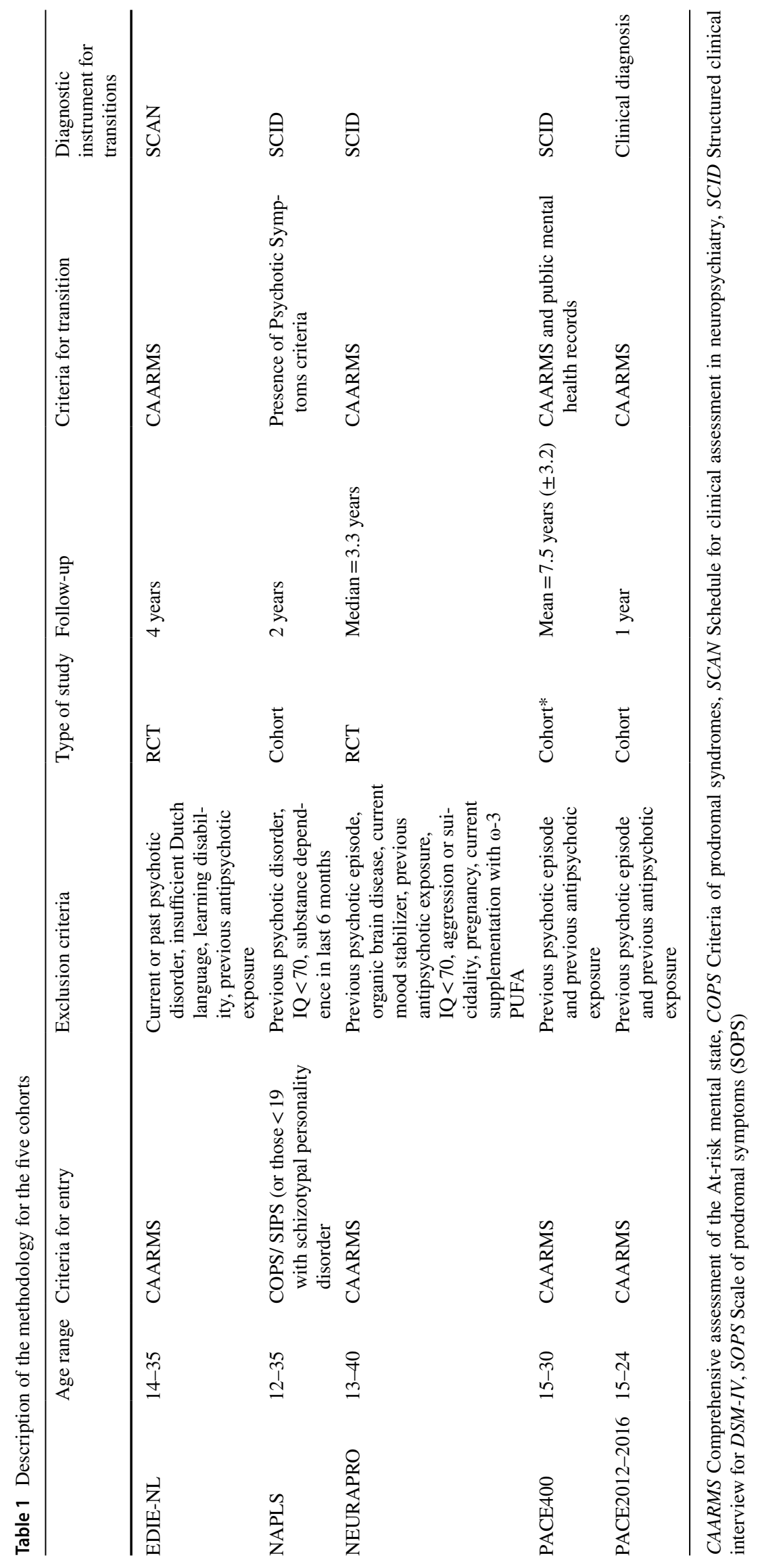


Clinical High Risk state [24] and transition to psychosis was determined using the Presence of Psychotic Symptoms criteria [25]. A summary of the methodology utilized in each of the five studies is presented in Table 1.

\section{Statistical analysis}

To undertake the meta-analysis, the hazard ratios for the risk of transition were calculated from the five individual cohorts. There was variable time to follow-up for all individuals in each cohort and therefore, Cox regression analysis was performed to determine hazard ratios for predictor variables. The outcome was the binary variable of 'transition' to psychotic disorder and the time to event was the number of days from the entry to study to the time of transition or last known timepoint at which it was known that the individual had not transitioned to a psychotic disorder. Three different statistical analyses were performed. In the first, the hazard ratios for transition were determined in the first-generation migrant group compared to the native-born populations. However, as the native-born populations also included the second-generation migrant population (which could have its own specific risk profile), a second analysis was performed to determine the hazard ratios for transition in the first-generation migrant group compared to the nativeborn populations excluding the second-generation migrants. Finally, a third analysis was performed determining the hazard ratios for transition in the second-generation migrant group compared to the remainder of the native-born populations. Each model was controlled for sex and age. For one of the cohorts (PACE2012-2016) there was no data pertaining to second-generation status and therefore, this cohort was not used in the second and third analyses. The initial statistical analysis plan had been to pool the individual data and analyze it as one large, combined cohort; however, as there was significant heterogeneity between studies, a metaanalysis approach was deemed to be more appropriate. The log hazard ratios and standard errors were obtained from the above analysis of the individual studies and were used to conduct a meta-analysis using the generic inverse-variance method using a random-effects model. The Cox Regression analysis was performed in SPSS v26.0 [26] and the metaanalysis was conducted using Review Manager (Rev Man) Version 5.4 [27].

\section{Ethical approval}

The cohort study consists of participants from five different studies, two of which were randomized controlled studies. Participants of the NEURAPRO trial, EDIE-NL trial, PACE400 study and NAPLS study provided written informed consent. The second cohort from the PACE clinic was a cohort of all young people who attended the PACE clinic and in order to obtain information on all individuals, a waiver of consent was granted by the local ethics committee (Melbourne Health HREC: project ID: F16-241). These studies were conducted in adherence to the 1964 Declaration of Helsinki and its later amendments.

\section{Results}

\section{Description of participants}

Data pertaining to 2166 individuals identified as UHR were obtained, with a mean age of 19.1 years $(S D \pm 4.5)$ and $50.1 \%(n=1086)$ were males. A total of $89.6 \%$ of the cohort fulfilled the criteria for the attenuated psychotic symptoms group, 5.4\% had brief limited intermitted psychotic symptoms and $18.1 \%$ fulfilled the criteria for vulnerability for psychosis and low functioning (individuals could fulfill criteria for more than one group). Two hundred and twentyone $(10.7 \%)$ young people were first-generation migrants. Of the 1843 participants who were native-born, there were data available for $77.6 \%(N=1430)$ regarding second-generation migrant status and it was found that $22.9 \%(N=365)$ of this group were second-generation migrants. A description of the participants is presented in Table 2.

\section{Migrant status and transition to psychosis}

Over a median follow-up time of 417 days (I.Q.R. 147-756 days), 357 individuals were found to have transitioned to a full-threshold psychotic disorder, representing $17.0 \%$ of the total cohort. A total of $16.7 \%(N=37)$ of first-generation migrants were known to have transitioned to a full-threshold psychotic disorder within the followup period, while $21.6 \%(N=79)$ of the second-generation migrants transitioned. The hazard ratios for the risk of transition in each individual cohort are presented in Table 3.

\section{Meta-analysis}

In the meta-analysis, the hazard ratio for the risk of transition in first-generation migrants compared to the nativeborn populations was 1.08 (95\% CI 0.62-1.89) and when the second-generation migrants were removed from the nativeborn population group, the hazard ratio was 1.16 (95\% CI 0.46-2.88). The hazard ratio for the risk of transition in second-generation migrants compared to the remainder of the native-born population was 1.03 (95\% CI 0.70-1.51). The results of the three meta-analyses models are presented in Table 4. 
Table 2 Characteristics of participants

\begin{tabular}{|c|c|c|}
\hline \multirow[b]{2}{*}{ Sex } & \multicolumn{2}{|l|}{$\begin{array}{l}\text { Total } \\
\text { cohort }\end{array}$} \\
\hline & $N$ & $\%$ \\
\hline Male & 1086 & 50.1 \\
\hline Female & 1080 & 49.9 \\
\hline & Mean & $\mathrm{SD}$ \\
\hline Age & 19.1 & 4.5 \\
\hline Cohort & $N$ & $\%$ \\
\hline EDIE-NL & 201 & 9.3 \\
\hline NAPLS & 764 & 35.3 \\
\hline NEURAPRO & 304 & 14.0 \\
\hline PACE400 & 416 & 19.2 \\
\hline PACE2012-2016 & 481 & 22.2 \\
\hline \multicolumn{3}{|l|}{ Place of Recruitment } \\
\hline Australia (Melbourne) & 1003 & 46.3 \\
\hline Australia (Sydney) & 11 & 0.5 \\
\hline Austria (Vienna) & 72 & 3.3 \\
\hline Canada (Calgary, Alberta) & 151 & 7.0 \\
\hline Denmark (Copenhagen) & 15 & 0.7 \\
\hline Germany (Jena) & 36 & 1.7 \\
\hline Hong Kong & 11 & 0.5 \\
\hline Netherlands (Amsterdam) & 67 & 3.0 \\
\hline Netherlands (Friesland) & 29 & 1.3 \\
\hline Netherlands (Leiden) & 24 & 1.1 \\
\hline Netherlands (The Hague) & 90 & 4.2 \\
\hline Netherlands (Utrecht) & 2 & 0.1 \\
\hline Singapore & 15 & 0.7 \\
\hline Switzerland (Basel) & 9 & 0.4 \\
\hline Switzerland (Zurich) & 13 & 0.6 \\
\hline USA (Atlanta, Georgia) & 89 & 4.1 \\
\hline USA (Boston, Massachusetts) & 55 & 2.5 \\
\hline USA (Chapel Hill, North Carolina) & 91 & 4.2 \\
\hline USA (Long Island, New York) & 85 & 3.9 \\
\hline USA (Los Angeles, California) & 108 & 5.0 \\
\hline USA (New Haven, Connecticut) & 94 & 4.3 \\
\hline USA (San Diego, California) & 91 & 4.2 \\
\hline Missing & 5 & 0.2 \\
\hline \multicolumn{3}{|l|}{ UHR criteria* } \\
\hline Attenuated psychotic symptoms & 1668 & 89.6 \\
\hline Brief Limited Intermittent Psychotic symptoms & 101 & 5.4 \\
\hline Vulnerability and low functioning & 337 & 18.1 \\
\hline Schizotypal & 75 & 9.8 \\
\hline \multicolumn{3}{|l|}{ Migrant status $* *$} \\
\hline First-generation migrant & 221 & 10.7 \\
\hline Native-born & 1843 & 89.3 \\
\hline Second-generation migrants within native-born group & 365 & 25.5 \\
\hline
\end{tabular}

*Data were available for $85.9 \%$ of cohort in regards to APS, BLIPS and vulnerability and functioning groups and for $35.3 \%$ in regards to Schizotypal personality disorder

** Data available for $95.3 \%$ of cohort in regards to migrant status and there was information on $77.6 \%$ of the native-born population group on second-generation migrant status

\section{Discussion}

\section{Summary of findings}

In this meta-analysis that included participants from a large number of international sites, no statistically significant association was found between UHR status and an increased risk for transition to a full-threshold psychotic disorder. However, there was considerable heterogeneity between studies and migrants were also considered as a homogenous group, which are both limitations to this meta-analysis.

\section{Possible explanations for the findings}

These findings are intriguing and counter-intuitive, as it is well established that migrants are at an increased risk of developing a psychotic disorder; therefore, it would be expected that there would either be a higher rate of migrants identified as UHR or that they have an increased risk for transition. It does need to be highlighted that the hazard ratios were in the direction of an increased risk for transition in migrants; interestingly, when secondgeneration migrants were removed from the comparison group, the risk for transition in first-generation migrants increased from 1.08 to 1.16 , although both findings were not statistically significant.

There are several possible explanations for these findings. First, migrants may be less likely to be identified as being UHR and hence they will be under-represented in the UHR clinics and this was demonstrated in one of the cohorts included in this study [17]. Considering that this population is over-represented in the first episode of psychosis cohorts, it would likely mean that migrants are more likely to enter these clinics directly. This is a likely explanation, considering that migrants are more likely to be unfamiliar with the local mental health services and have more barriers to enter care [28], and it is known that migrants have longer delays to treatment. This study demonstrated that migrants have a similar rate of transition to the native-born population and yet migrants are over-represented in first episode cohorts. Another explanation for the findings of this study is the possibility of a selection bias within the cohorts. In research studies, proficiency in the host language is often an inclusion criterion and considering that some migrants may only exclusively speak their native language, it is possible that migrants are under-represented within research studies. This is a distinct possibility in the current study, as a number of the studies were controlled trials, which generally include this criterion. Furthermore, it needs to be considered that 
Table 3 Risk of transition in each individual cohort

\begin{tabular}{|c|c|c|c|c|c|c|c|c|}
\hline & & \multicolumn{2}{|c|}{ Transitioned } & \multicolumn{2}{|c|}{$\begin{array}{l}\text { Did not } \\
\text { transition }\end{array}$} & \multirow[t]{2}{*}{ aHR } & \multirow[t]{2}{*}{$95 \% \mathrm{CI}$} & \multirow[t]{2}{*}{$\mathrm{p}$} \\
\hline & & $N$ & $\%$ & $N$ & $\%$ & & & \\
\hline \multicolumn{9}{|c|}{ Risk in first-generation migrant group compared to native-born population } \\
\hline \multirow[t]{2}{*}{ EDIE-NL } & Native-born & 23 & 13.5 & 147 & 86.5 & & & \\
\hline & First-generation migrant & 9 & 30.0 & 21 & 70.0 & 2.33 & $1.02-5.31$ & 0.045 \\
\hline \multirow[t]{2}{*}{ NAPLS } & Native-born & 84 & 12.2 & 607 & 87.8 & & & \\
\hline & First-generation migrant & 9 & 14.1 & 55 & 85.9 & 1.19 & $0.60-2.39$ & 0.62 \\
\hline \multirow[t]{2}{*}{ NEURAPRO } & Native-born & 39 & 14.4 & 232 & 85.6 & & & \\
\hline & First-generation migrant & 0 & 0 & 26 & 100 & - & & \\
\hline \multirow[t]{2}{*}{ PACE400 } & Native-born & 100 & 32.7 & 206 & 67.3 & & & \\
\hline & First-generation migrant & 6 & 15.8 & 32 & 84.2 & 0.44 & $0.19-1.01$ & 0.05 \\
\hline \multirow[t]{2}{*}{ PACE2012-16 } & Native-born & 74 & 18.3 & 330 & 81.7 & & & \\
\hline & First-generation migrant & 13 & 20.6 & 50 & 79.4 & 1.09 & $0.59-2.03$ & 0.78 \\
\hline \multicolumn{9}{|c|}{$\begin{array}{l}\text { Risk in first-generation migrant group compared to native-born population excluding second-generation } \\
\text { migrants (SGM) }\end{array}$} \\
\hline \multirow[t]{2}{*}{ EDIE-NL } & Native-born (excl SGM) & 13 & 11.5 & 100 & 88.5 & & & \\
\hline & First-generation migrant & 9 & 30.0 & 21 & 70.0 & 3.00 & $1.16-7.77$ & 0.02 \\
\hline \multirow[t]{2}{*}{ NAPLS } & Native-born (excl SGM) & 76 & 12.5 & 530 & 87.5 & & & \\
\hline & First-generation migrant & 9 & 14.1 & 55 & 85.9 & 1.18 & $0.58-2.36$ & 0.65 \\
\hline \multirow[t]{2}{*}{ NEURAPRO } & Native-born (excl SGM) & 26 & 14.1 & 159 & 85.9 & & & \\
\hline & First-generation migrant & 0 & 0 & 26 & 100 & - & & \\
\hline \multirow[t]{2}{*}{ PACE400 } & Native-born (excl SGM) & 46 & 28.7 & 114 & 71.3 & & & \\
\hline & First-generation migrant & 6 & 15.8 & 32 & 84.2 & 0.46 & $0.20-1.09$ & 0.08 \\
\hline \multicolumn{9}{|c|}{ Risk in second-generation migrant group compared to rest of native-born population } \\
\hline \multirow[t]{2}{*}{ EDIE-NL } & Rest of native-born pop & 13 & 11.5 & 100 & 88.5 & & & \\
\hline & Second-generation migrant & 10 & 17.5 & 47 & 82.5 & 1.56 & $0.63-3.87$ & 0.3430 \\
\hline \multirow[t]{2}{*}{ NAPLS } & Rest of native-born pop & 76 & 12.5 & 530 & 87.5 & & & \\
\hline & Second-generation migrant & 8 & 9.4 & 77 & 90.6 & 0.74 & $0.36-1.54$ & 0.42 \\
\hline \multirow[t]{2}{*}{ NEURAPRO } & Rest of native-born pop & 26 & 14.1 & 159 & 85.9 & & & \\
\hline & Second-generation migrant & 13 & 15.1 & 73 & 84.9 & 1.31 & $0.66-2.61$ & 0.45 \\
\hline \multirow[t]{2}{*}{ PACE400 } & Rest of native-born pop & 46 & 28.7 & 114 & 71.3 & & & \\
\hline & Second-generation migrant & 48 & 35.0 & 89 & 65.0 & 1.16 & $0.77-1.74$ & 0.47 \\
\hline
\end{tabular}

these findings are indeed 'true' and it may be the case that migrants are less likely to experience a prodrome or have a shorter prodrome and, therefore, present directly with a first episode of psychosis.

There are also two methodological issues that need to be considered when interpreting the results. The first is that in each of the individual studies, migrants were group together, implying that they are a homogenous group, when this is unlikely to be the case. Migrants can broadly consist of economic migrants, those looking for opportunities in another country or those may be seeing asylum. Those seeking asylum are known to have an increased risk for developing a psychotic disorder [29], however their risk for transition may not have been observed if the 'economic migrants' had a similar risk to the nativeborn population and thereby diluted the risk of the overall migrant group. Unfortunately, we did not have data as to whether migrants were seeking asylum or refugees in the individual cohorts. The other methodological issue that needs to be considered is that there was considerable heterogeneity between studies ( $>50 \%$ in each meta-analysis). As can be observed in Table 4, some studies identified that migrants had an increased risk of transition, while others found a reduced risk. As we know, migrants from different countries have different risk profiles, for example, in Australia, migrants from certain African countries have an inflated risk while migrants from certain Asian countries have a reduced risk [8]. Unfortunately, we did not have data pertaining to which countries migrants came from and it is possible that the risk of transition is related to the country of origin and the destination country and again by combining the migrant groups together, the risk in specific migrant groups was not identified. 
Table 4 Meta-analysis for risk of transition in first (models 1 and 2)- and second (model 3)-generation migrants

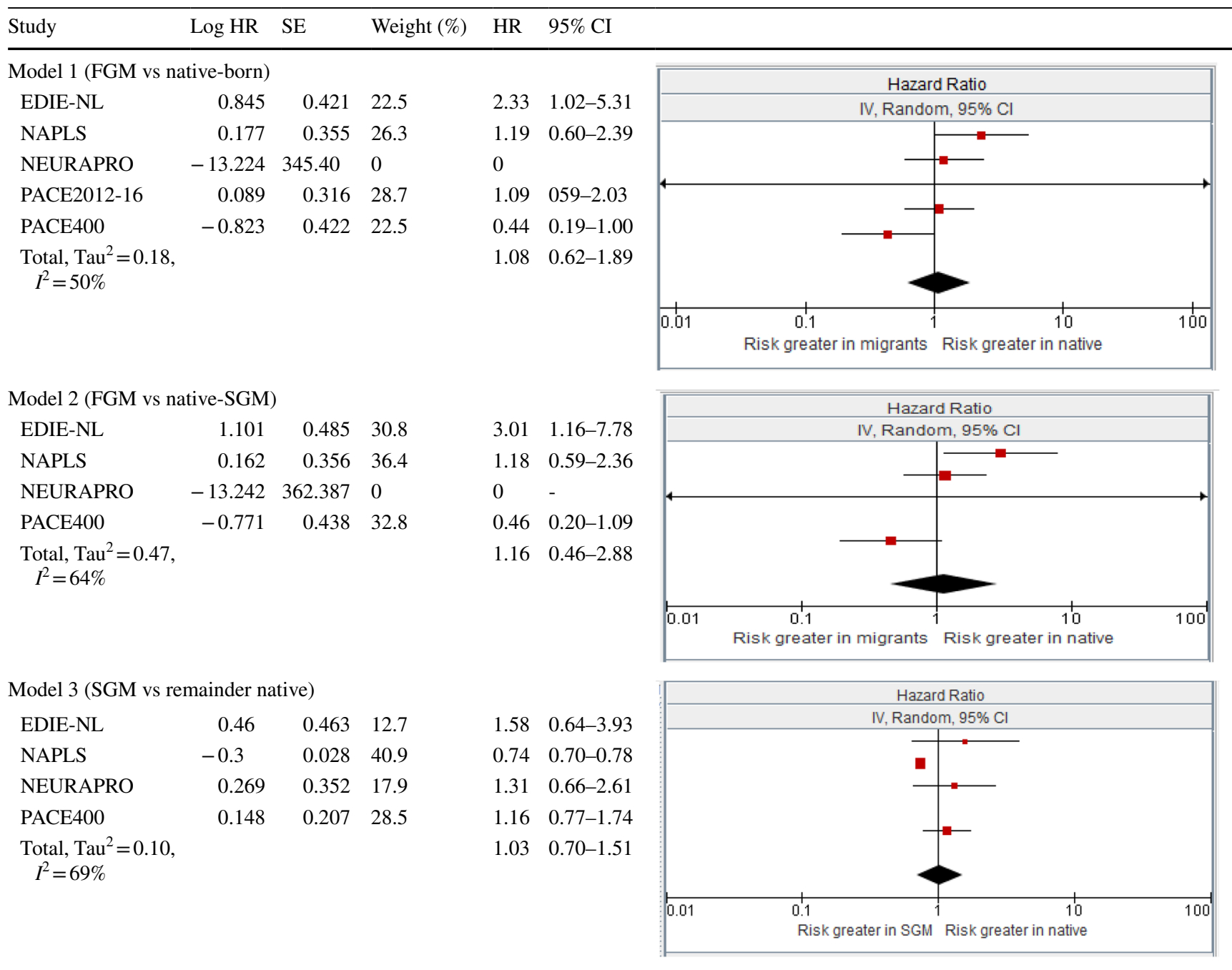

\section{Psychosis as a continuum}

Psychosis can be considered to exist on a continuum, with asymptomatic individuals or those experiencing sub-clinical psychotic symptoms at one end, and those with a full-threshold psychotic disorders such as schizophrenia at the other end of the spectrum. This postulates that the same psychotic symptoms present in psychosis can be seen in non-clinical populations [30] and it has been proposed that environmental risk factors should have an impact across this continuum. Indeed, it has been found that migrants are more likely to experience sub-clinical psychotic symptoms (often referred to as psychotic-like experiences or psychotic experiences) in Australia [31], Italy [32] and the UK [33]. Therefore, it is curious that migration would be a risk factor at both ends of the proposed continuum of psychosis and not in the prodromal stage of a psychotic disorder.

\section{Clinical and research implications}

One of the potential limitations to this study is that migrants may not be identified in the UHR or putative prodromal state. Therefore, it should be considered whether UHR cohorts should mirror FEP cohorts, i.e., have similar demographic characteristics and what effect this 'enrichment' of the cohort may have on transition rates. For example, females tend to be over-represented in UHR cohorts [34], yet males are over-represented in FEP cohorts of similar age groups [35]. Transition rates are declining within UHR cohorts and one of the hypotheses is that cohorts are being 'diluted' with individuals who are at lower risk of progressing to a full-threshold psychotic disorder. Future research could adjust the UHR criteria or employ strategies to identify UHR cases in such a way to ensure that migrants are appropriately represented. 


\section{Strengths and limitations}

The strengths of this study include the large sample size and the use of well-validated and reliable instruments to identify the outcome of transition. However, the findings need to be considered within the limitations. First, migrants were classified in a dichotomous manner (migrant/non-migrant) resulting in economic migrants being grouped together with migrants who were forced to seek asylum and it is likely that these groups would have had different experiences migrating and settling into the new country. Second, a large proportion of the cases came from one site (Melbourne, Australia), which could limit the representativeness. Third, in each of the individual studies, the time at presentation or entry to the specific study was used as the beginning of the time period for the Cox regression; however, it is likely that individuals would have experienced attenuated psychotic symptoms prior to this and for some, these may have been long periods Therefore, this starting point in the analysis is arbitrary and does not reflect the actual exposure periods. Finally, only one outcome (transition) was measured and while this is a critical outcome to examine, it is now recognized that UHR cohorts are susceptible to a range of negative outcomes, such as poor functioning, persistent attenuated psychotic symptoms and non-psychotic disorders, and these were not examined in the meta-regression.

\section{Conclusions}

This meta-analysis did not find an association between migrant status and an increased risk for transitioning to a full-threshold psychotic disorder compared to the nativeborn population who have been identified as UHR. There is a need for research examining whether young migrants are more or less likely to be identified as being UHR compared to the native-born populations and if found to be the case, then strategies should be employed to ensure migrants are appropriately represented within these clinical services.

\section{Compliance with ethical standards}

Conflict of interest The authors have no conflicts of interest to declare.

Data repository The data pertaining to this study have not been deposited in a data repository.

\section{References}

1. Cantor-Graae E, Selten J-P (2005) Schizophrenia and migration: a meta-analysis and review. Am J Psychiatry 162(1):12-24. https ://doi.org/10.1176/appi.ajp.162.1.12
2. Selten JP, van der Ven E, Termorshuizen F (2020) Migration and psychosis: a meta-analysis of incidence studies. Psychol Med 50(2):303-313. https://doi.org/10.1017/S0033291719000035

3. Odegaard O (1932) Emigration and insanity: a study of mental disorders among Norwegian-born population in Minnesota. Acta Psychiatr Neurol Scand 4:1-206

4. Cantor Graae E, Pedersen C, McNeil T, Mortensen P (2003) Migration as a risk factor for schizophrenia: a Danish populationbased cohort study. Br J Psychiatry 182:117-122

5. Selten JP, Slaets JP, Kahn RS (1997) Schizophrenia in Surinamese and Dutch Antillean immigrants to The Netherlands: evidence of an increased incidence. Psychol Med 27(4):807-811

6. Smith GN, Boydell J, Murray RM, Flynn S, McKay K, Sherwood M, Honer WG (2006) The incidence of schizophrenia in European immigrants to Canada. Schizophr Res 87(1-3):205-211. https:// doi.org/10.1016/j.schres.2006.06.024

7. Tortelli A, Errazuriz A, Croudace T, Morgan C, Murray RM, Jones PB, Szoke A, Kirkbride JB (2015) Schizophrenia and other psychotic disorders in Caribbean-born migrants and their descendants in England: systematic review and meta-analysis of incidence rates, 1950-2013. Soc Psychiatry Psychiatr Epidemiol 50(7):1039-1055. https://doi.org/10.1007/s00127-015-1021-6

8. O’Donoghue B, Downey L, Eaton S, Mifsud N, Kirkbride JB, McGorry P (2020) Risk of psychotic disorders in migrants to Australia. Psychol Med. https://doi.org/10.1017/S0033291719004100

9. Dykxhoorn J, Kirkbride JB (2019) Psychoses sans Frontieres: towards an interdisciplinary understanding of psychosis risk amongst migrants and their descendants. Epidemiol Psychiatr Sci 28(2):146-152. https://doi.org/10.1017/S2045796018000501

10. Anderson KK, Edwards J (2020) Age at migration and the risk of psychotic disorders: a systematic review and meta-analysis. Acta Psychiatr Scand 141(5):410-420. https://doi.org/10.1111/ acps. 13147

11. Yung AR, Nelson B (2013) The ultra-high risk concept-a review. Can J Psychiatry 58(1):5-12. https://doi.org/10.1177/0706743713 05800103

12. Yung AR, McGorry PD, McFarlane CA, Jackson HJ, Patton GC, Rakkar A (1996) Monitoring and care of young people at incipient risk of psychosis. Schizophr Bull 22(2):283-303

13. Yung ARPL, Yuen HP, Francey SM, McFarlane CA, Hallgren M, McGorry PD (2003) Psychosis prediction: 12-month follow up of a high-risk ("prodromal") group. Schizophr Res 60(1):21-32

14. Yung ARPL, Yuen HP, McGorry PD (2003) Risk factors for psychosis in an ultra high-risk group: psychopathology and clinical features. Schizophr Res 67(2):131-142

15. Fusar-Poli P, Bonoldi I, Yung AR, Borgwardt S, Kempton MJ, Valmaggia L, Barale F, Caverzasi E, McGuire P (2012) Predicting psychosis: meta-analysis of transition outcomes in individuals at high clinical risk. Arch Gen Psychiatry 69(3):220-229. https:// doi.org/10.1001/archgenpsychiatry.2011.1472

16. Addington J, Farris M, Stowkowy J, Santesteban-Echarri O, Metzak P, Kalathil MS (2019) Predictors of transition to psychosis in individuals at clinical high risk. Curr Psychiatry Rep 21(6):39. https://doi.org/10.1007/s11920-019-1027-y

17. Geros H, Sizer H, Mifsud N, Reynolds S, Kim DJ, Eaton S, McGorry P, Nelson B, O'Donoghue B (2020) Migrant status and identification as ultra-high risk for psychosis and transitioning to a psychotic disorder. Acta Psychiatr Scand 141(1):52-59. https:// doi.org/10.1111/acps.13099

18. O'Donoghue B, Nelson B, Yuen HP, Lane A, Wood S, Thompson A, Lin A, McGorry P, Yung AR (2015) Social environmental risk factors for transition to psychosis in an ultra-high risk population. Schizophr Res 161(2-3):150-155. https://doi.org/10.1016/j.schre s.2014.10.050

19. Ising HK, Kraan TC, Rietdijk J, Dragt S, Klaassen RM, Boonstra N, Nieman DH, Willebrands-Mendrik M, van den Berg DP, 
Linszen DH, Wunderink L, Veling W, Smit F, van der Gaag M (2016) Four-year follow-up of cognitive behavioral therapy in persons at ultra-high risk for developing psychosis: the dutch early detection intervention evaluation (EDIE-NL) trial. Schizophr Bull 42(5):1243-1252. https://doi.org/10.1093/schbul/sbw018

20. Addington J, Liu L, Buchy L, Cadenhead KS, Cannon TD, Cornblatt BA, Perkins DO, Seidman LJ, Tsuang MT, Walker EF, Woods SW, Bearden CE, Mathalon DH, McGlashan TH (2015) North American prodrome longitudinal study (NAPLS 2): the prodromal symptoms. J Nerv Ment Dis 203(5):328-335. https://doi. org/10.1097/NMD.0000000000000290

21. McGorry PD, Nelson B, Markulev C, Yuen HP, Schafer MR, Mossaheb N, Schlogelhofer M, Smesny S, Hickie IB, Berger GE, Chen EY, de Haan L, Nieman DH, Nordentoft M, Riecher-Rossler A, Verma S, Thompson A, Yung AR, Amminger GP (2017) Effect of omega-3 polyunsaturated fatty acids in young people at ultrahigh risk for psychotic disorders: the NEURAPRO randomized clinical trial. JAMA Psychiatry 74(1):19-27. https://doi.org/10.1001/ jamapsychiatry.2016.2902

22. Nelson B, Yuen HP, Wood SJ, Lin A, Spiliotacopoulos D, Bruxner A, Broussard C, Simmons M, Foley DL, Brewer WJ, Francey SM, Amminger GP, Thompson A, McGorry PD, Yung AR (2013) Long-term follow-up of a group at ultra high risk ("prodromal") for psychosis: the PACE 400 study. JAMA Psychiatry 70(8):793802. https://doi.org/10.1001/jamapsychiatry.2013.1270

23. Yung AR, Yuen HP, McGorry PD, Phillips LJ, Kelly D, Dell'Olio M, Francey SM, Cosgrave EM, Killackey E, Stanford C, Godfrey K, Buckby J (2005) Mapping the onset of psychosis: the comprehensive assessment of at-risk mental states. Aust $\mathrm{N}$ Z J Psychiatry 39(11-12):964-971. https://doi.org/10.108 0/j.1440-1614.2005.01714.x

24. MacGlashan TW, Walsh BC, Woods SW (2010) The psychosis risk syndrome: handbook for diagnosis and follow-up. Oxford University Press, New York

25. Miller TJ, McGlashan TH, Rosen JL, Cadenhead K, Cannon T, Ventura J, McFarlane W, Perkins DO, Pearlson GD, Woods SW (2003) Prodromal assessment with the structured interview for prodromal syndromes and the scale of prodromal symptoms: predictive validity, interrater reliability, and training to reliability.
Schizophr Bull 29(4):703-715. https://doi.org/10.1093/oxfordjour nals.schbul.a007040

26. IBM Corporation (2019) IBM SPSS Statistics for Windows Version 26.0. Armonk, NY

27. The_Cochrane-Collaboration (2020) Review Manager (Rev Man) 5.4 edn

28. Boonstra N, Sterk B, Wunderink L, Sytema S, De Haan L, Wiersma D (2012) Association of treatment delay, migration and urbanicity in psychosis. Eur Psychiatry J Assoc Eur Psychiatr 27(7):500-505. https://doi.org/10.1016/j.eurpsy.2011.05.001

29. Dapunt J, Kluge U, Heinz A (2017) Risk of psychosis in refugees: a literature review. Translational psychiatry 7(6):e1149-e1149. https://doi.org/10.1038/tp.2017.119

30. van Os J, Linscott RJ, Myin-Germeys I, Delespaul P, Krabbendam L (2009) A systematic review and meta-analysis of the psychosis continuum: evidence for a psychosis proneness-persistenceimpairment model of psychotic disorder. Psychol Med 39(2):179_ 195. https://doi.org/10.1017/S0033291708003814

31. Scott J, Chant D, Andrews G, McGrath J (2006) Psychotic-like experiences in the general community: the correlates of CIDI psychosis screen items in an Australian sample. Psychol Med 36(2):231-238. https://doi.org/10.1017/S0033291705006392

32. Tarricone I, Atti AR, Salvatori F, Braca M, Ferrari S, Malmusi D, Berardi D (2009) Psychotic symptoms and general health in a socially disadvantaged migrant community in Bologna. Int J Soc Psychiatry 55(3):203-213. https://doi.org/10.1177/0020764008 093445

33. King M, Nazroo J, Weich S, McKenzie K, Bhui K, Karlsen S, Stansfeld S, Tyrer P, Blanchard M, Lloyd K, McManus S, Sproston K, Erens B (2005) Psychotic symptoms in the general population of England-a comparison of ethnic groups (The EMPIRIC study). Soc Psychiatry Psychiatr Epidemiol 40(5):375-381

34. Nelson B, Yuen K, Yung AR (2011) Ultra high risk (UHR) for psychosis criteria: Are there different levels of risk for transition to psychosis? Schizophr Res 125(1):62-68. https://doi.org/10.1016/j. schres.2010.10.017

35. Larsen TK, McGlashan TH, Moe LC (1996) First-episode schizophrenia: I. Early course parameters. Schizophr Bull 22(2):241-256

\section{Affiliations}

Brian O'Donoghue ${ }^{1,2}(1) \cdot$ Hellen Geros ${ }^{1,2} \cdot$ Holly Sizer $^{1,2} \cdot$ Jean Addington ${ }^{3} \cdot$ G. Paul Amminger ${ }^{1,2,4} \cdot$ Carrie E. Beaden $^{5}$. Kristin S. Cadenhead ${ }^{6} \cdot$ Tyrone D. Cannon $^{7}$. Barbara A. Cornblatt ${ }^{8}$. Gregor Emanuel Berger ${ }^{9} \cdot$ Eric Y. H. Chen ${ }^{10}$. Lieuwe de Haan ${ }^{11}$. Jessica A. Hartmann ${ }^{1,2}$. Ian B. Hickie ${ }^{12}$. Helga K. Ising ${ }^{13}$. Suzie Lavoie ${ }^{1,2}$. Ashleigh Lin ${ }^{14}$. Connie Markulev ${ }^{1,2}$. Daniel H. Mathalon ${ }^{15,16}$. Thomas H. McGlashan ${ }^{17}$. Nathan G. Mifsud ${ }^{1,2}$. Nilufar Mossaheb ${ }^{4}$. Dorien H. Nieman ${ }^{11}$. Merete Nordentoft ${ }^{18}$. Diana O. Perkins ${ }^{19}$. Anita Riecher-Rössler ${ }^{20}$. Miriam R. Schäfer ${ }^{1,2}$. Monika Schlögelhofer ${ }^{4}$. Larry J. Seidman ${ }^{21,22}$. Stephan Smesny ${ }^{23}$. Andrew Thompson ${ }^{1,2}$ • Ming T. Tsuang ${ }^{6}$. Mark van der Gaag ${ }^{13,24}$. Swapna Verma ${ }^{25}$. Elaine F. Walker ${ }^{26}$. Stephen J. Wood ${ }^{1,2}$. Scott W. Woods ${ }^{17}$. Hok Pan Yuen ${ }^{1,2}$. Alison Ruth Yung ${ }^{1,2,27}$. Patrick D. McGorry ${ }^{1,2}$. Barnaby Nelson ${ }^{1,2}$

1 Orygen, Melbourne, Australia

2 Centre for Youth Mental Health, University of Melbourne, Melbourne, Australia

3 Department of Psychiatry, Hotchkiss Brain Institute, University of Calgary, Calgary, AB, Canada

4 Department of Psychiatry, Medical University of Vienna, Vienna, Austria
5 Department of Psychiatry and Biobehavioral Sciences, UCLA, Los Angeles, CA, USA

6 Department of Psychiatry, UCSD, San Diego, CA, USA

7 Department of Psychology, Yale University, New Haven, CT, USA

8 Department of Psychiatry, Zucker Hillside Hospital, Long Island, NY, USA 
9 Child and Adolescent Psychiatric Service of the Canton of Zurich, Zürich, Switzerland

10 Department of Psychiatry, University of Hong Kong, Pok Fu Lam, Hong Kong

11 Department of Psychiatry, Academic Medical Center, Amsterdam, The Netherlands

12 Brain and Mind Research Institute, University of Sydney, Sydney, Australia

13 Department of Psychosis Research, Parnassia Psychiatric Institute, The Hague, The Netherlands

14 Telethon Kids Institute, Perth, Australia

15 Department of Psychiatry, UCSF, San Francisco, CA, USA

16 SFVA Medical Center, San Francisco, CA, USA

17 Department of Psychiatry, Yale University, New Haven, CT, USA

18 Psychiatric Centre Bispebjerg, Copenhagen, Denmark
19

Department of Psychiatry, University of North Carolina, Chapel Hill, NC, USA

20 Psychiatric University Clinics Basel, Basel, Switzerland

21 Department of Psychiatry, Harvard Medical School at Beth Israel Deaconess Medical Center, Boston, MA, USA

22 Massachusetts General Hospital, Boston, MA, USA

23 Department of Psychiatry, University Hospital Jena, Jena, Germany

24 Department of Clinical, Neuro and Developmental Psychology, Amsterdam Public Health Research Institute, Vrije Universiteit, Amsterdam, The Netherlands

25 Institute of Mental Health, Singapore, Singapore

26

Department of Psychology, Emory University, Atlanta, GA, USA

27 Institute of Brain, Behaviour and Mental Health, University of Manchester, Manchester, England 